\title{
Patient Parents: Do Offspring Decide on the Timing of Fledging in Zebra Finches?
}

\author{
Fritz Trillmich*, Inka Spiller*, Marc Naguib $\uparrow \&$ Eike Tobias Krause* \\ * Department of Animal Behaviour, University of Bielefeld, Bielefeld, Germany \\ $\uparrow$ Behavioural Ecology Group, Wageningen University, Wageningen, The Netherlands \\ * Institute of Animal Welfare and Animal Husbandry, Friedrich-Loeffler-Institut, Celle, Germany
}

\section{Correspondence}

Fritz Trillmich, University of Bielefeld, Department of Animal Behaviour, Morgenbreede 45, D-33615 Bielefeld, Germany.

E-mail: fritz.trillmich@uni-bielefeld.de

Received: December 16, 2015

Initial acceptance: January 14, 2016

Final acceptance: February 11, 2016

(J. Wright)

doi: $10.1111 /$ eth. 12490

Keywords: parent-offspring conflict, timing of fledging, parental care, weaning, transition to independence

\begin{abstract}
Parent-offspring conflict over parental care is predicted to become most pronounced during offspring transition to independence when offspring are predicted to attempt to extend care for longer than parents are selected to provide it. However, on the proximate level, it is difficult to determine who plays the most important role in this process, parents or offspring. For several vertebrate taxa, it has been documented that parents end brood care by abandoning offspring after a fixed period or else show high flexibility in the duration of care, but teasing apart the role of offspring and parents underlying this flexibility has been difficult. Here, we studied the decision to fledge in captive zebra finches (Taeniopygia guttata), an altricial songbird. We experimentally delayed the time of fledging to determine who decides about the end of feeding inside the nest, parents or offspring. The experiment indicates that parents do not primarily rely on phenotypic offspring traits in their decision to feed offspring in the nest, but appear to adjust the duration of parental care as long as offspring are in the nest which parents may take as an indicator of offspring need and locomotor abilities. Delayed-fledging offspring appeared not to suffer a disadvantage in terms of age at the onset of independent feeding. Our study suggests that, in zebra finches, offspring play a major role in determining the time of fledging and leave the nest on their own, possibly to reduce the risk of nest predation, or to evade sibling competition in the nest.
\end{abstract}

\section{Introduction}

The transition to independence from parental care is a critical period in the development of a young animal (Lindström 1999; Mainwaring \& Hartley 2012). From the offspring's point of view, individuals may be able to increase individual fitness, if they can extend the period of parental care. Yet, extended parental care may also incur costs in terms of inclusive fitness by reducing the parents' probability of subsequent reproduction, if offspring manipulate them into lengthening the brood care period beyond the parental optimum. Likewise, parents may incur costs in terms of reduced survival or future fertility, if prolonged brood care is induced by their offspring. On the other hand, parents may benefit if they respond plastically to offspring need such as when young develop slower than normal due to poor environmental or nutritional conditions (Metcalfe \& Monaghan, 2001). Independent of the question whether plasticity in the decision processes of parent and offspring reflects coadaptation due to parent-offspring conflict or reflects cooperation (Smiseth et al. 2008; Bossan et al. 2013); there is little research specifically addressing on the proximate level the role of both parties during this transition.

For several taxa, it has been shown that parents may determine the end of brood care by abandoning offspring after a fixed period of care (birds: Grim 2007; Johnsen et al. 1994; mammals: Rehling \& Trillmich 2007, 2008a,b) or show high plasticity in 
the duration of care in response to variation in offspring development (birds: Kilner \& Hinde 2012; Nilsson \& Svensson 1993; Rehling et al. 2012; Soler et al. 2013; invertebrates: Leigh \& Smiseth 2012; Wong \& Kölliker 2012). In experimental studies on birds and mammals, cross-fostering of young differing in age from the mother's own offspring has proven a valuable tool to disentangle the behavioural processes around the timing of fledging or weaning (Grim 2007; Rehling \& Trillmich 2007; Rehling et al. 2012). If parents continue care beyond their normal care period when given younger offspring, this would suggest that the offspring are responsible for the normal transition to independence. In contrast, if parents end brood care at a standard time, even when given younger offspring, this would suggest a decisive role of parents on the transition to independence. If parents end brood care before their own natural care period when given older offspring than their own, they likely base their decision on the appearance or behaviour of the offspring.

Exploring this question can provide crucial information about the behavioural mechanisms that end the parental care period. To understand the mechanism involved in the termination of parental care inside the nest, we need to know more about parental sensitivity to offspring demand and the offspring's sensitivity to variability in supply (Kilner \& Hinde 2012). Clearly parents need to be sensitive to the demands of offspring, but at the same time this bears the risk of exploitation (Parker \& MacNair 1979). Notwithstanding parental sensitivity to offspring state, in some species parents apparently encouraged offspring to leave the nest by reducing feeding frequency (Grim 2007). In seabirds, this may be explained by the high cost to parents of transporting food from far off marine foraging grounds to the nest on land (Fratercula arctica, Johnsen et al. 1994; Puffinus puffinus, Riou et al. 2012). In these species, parents may decide to encourage offspring to leave the nest because of increasing difficulties to provide sufficient supplies to the nest site. Parental decisions might also be based on some kind of an internal clock mechanism, which tells parents how long they have been caring (Grim 2007; Rehling \& Trillmich 2007; Riou et al. 2012), or on cues reflecting offspring developmental state. Alternatively, it may not be the parents who decide about the time to fledge or wean, but instead offspring may use information about a decline in food supply, or their own developmental state to decide when to fledge or wean (Bowers et al. 2013).

In birds, cross-fostering experiments, where offspring of different ages were swapped, have resulted in widely different findings. In some seabirds, the parents usually seem to decide about the length of brood care in the nest (Johnsen et al. 1994; Riou et al. 2012), whereas in passerines often nestlings may be responsible for the timing of fledging (Litovich $\delta$ Power 1992; Nilsson \& Svensson 1993; Bowers et al. 2013; Soler et al. 2013; but see Grim 2007). Yet, previous studies did not exclude the interpretation that parents enforce fledging by reducing their feeding activity at the nest once chicks present the features (visual/acoustic/olfactory stimuli) that indicate readiness to fledge. To distinguish this case, where both parties, parent and offspring, are involved in the fledging process, from the case where offspring on their own decide to fledge for reasons not induced by parental changes in brood care, a specific experimental approach is required.

We here study fledging in captive zebra finches (Taeniopygia guttata), an altricial songbird where parents appear to be in 'a position of power' as they bring food to the nest and distribute it among nestlings (Zann 1996; Gilby et al. 2011; Rehling et al. 2012). Young zebra finches use a combination of acoustic, visual and behavioural begging signals to solicit food from the parents (Immelmann et al. 1977; Muller \& Smith 1978; von Engelhardt et al. 2006; Levrero et al. 2009; Krause et al. 2011). After fledging (around day 18-20), offspring are further fed outside the nest and become nutritionally independent of their parents at approximately the age of $35 \mathrm{~d}$ (Zann 1996). According to this sequence of events, we call offspring in the nest 'nestlings', and once they have left the nest 'fledglings'. In this species, parents have been shown to extend or shorten the period of parental care inside the nest in response to protracted or shortened demand (Rehling et al. 2012). The authors obtained these results by cross-fostering younger and older nestlings and measuring the feeding activity of parents. The study demonstrated substantial parental plasticity in the duration of brood care in the nest and suggested that such plasticity might have evolved as a response to unpredictable feeding conditions and the consequent variable development of nestlings. However, in their experiments, all nestlings fledged at the same average age of 19-20 d, even when in cross-fostered younger nestlings fledging weight was reduced (Rehling et al. 2012).

This leaves open the question whether or not, on the proximate level, it is parental or nestling traits that induce the end of parental care inside the nest. The results of Rehling et al. (2012) clearly showed that parents are prepared to feed nestlings for longer than normal inside the nest, as long as they provide the 
features typical of nestlings in the (late) nestling stage. However, their data do not exclude the possibility that parents may use chick appearance as a cue to end feeding in the nest. If so, this would encourage chicks to leave the nest and would indicate that parents induce fledging. Thus, two hypotheses seem possible: (1) Parents may enforce fledging once nestlings have reached a certain developmental stage, which parents may recognize by morphological or behavioural cues. Alternatively, (2) offspring may have evolved to leave the nest on their own once they have reached a certain developmental stage, for example, due to a reduced risk of mortality outside the nest (Martin et al. 2000; Roff et al. 2005). Another reason for offspring to leave the nest could be to obtain a larger share of parental feeding than siblings by intercepting parents before they enter the nest (Soler et al. 2013).

Here, we tested whether parents continue to feed chicks that delay fledging. We predicted that whether offspring determine the duration of parental care that delayed fledglings would still be fed by parents and reach equal body mass as normally fledged nestlings.

\section{Methods}

The experiment was carried out on an outbred population of zebra finches kept at the University of Bielefeld, Germany, which cluster genetically with wild Australian birds (Forstmeier et al. 2007). Pairs $(\mathrm{n}=32)$ were kept in cages measuring $80 \times 35 \times 40$ (high) cm. For breeding, a wooden nest box $(15 \times 15 \times 15 \mathrm{~cm})$ was attached outside of the cage and coconut fibres were provided as nest building material. Mixed seeds, millet spray, water, oyster grit and cuttlebone were provided ad libitum. Egg supplement and greens were given three times a week. Birds were kept under a light:dark cycle of 14:10 h at room temperatures of approximately $22^{\circ} \mathrm{C}$.

Nests were checked daily from egg-laying until offspring were nutritionally independent. Hatchlings were weighed (Sartorius PT120 $\pm 0.01 \mathrm{~g}$ ) and individually marked by clipping down feathers (Naguib et al. 2004; Adam et al. 2014). At day 10, nestlings were ringed with numbered plastic rings. We determined mean fledging day per brood, that is the mean age of chicks when first observed outside the nest and mean fledging mass per brood. The nestling period per brood was defined, in line with Rehling et al. (2012), as the period from mean hatching day until mean fledging day. Breeding pairs were assigned to either a control group or an experimental group which were run simultaneously in the same room. In the control group ( $\mathrm{N}=27$ broods), nestlings of the same age
( $\pm 2 \mathrm{~d}$ ) as a pair's original nestlings were cross-fostered between broods ( $\mathrm{N}=13$ broods) or nestlings were taken from the nest and immediately placed back ( $\mathrm{N}=14$ broods). The latter manipulation was done at the same age as the cross-fostering in the other pairs of the control group. As we found no statistical differences in any parameter between these controls (all p > 0.09), we combined the two groups into one 'control' group (Rehling et al. 2012). Previous experiments have demonstrated that zebra finch parents readily accept foster chicks (Naguib et al. 2004; Krause et al. 2012; Rehling et al. 2012). After day 35 , that is when young are nutritionally independent (Zann 1996), families of the control were separated and all birds transferred into group aviaries.

In the five experimental broods, to determine whether parents would reduce feeding when chicks in the nest are fully feathered and look like fledglings, we retained chicks in the nest beyond the normal fledging age of 18-20 d (Rehling et al. 2012), never exceeding day 26 post-hatching of the brood. To keep these nestlings in the nest beyond their normal fledging age, on day 17 we increased the depth of the nest cup by removing the nest material at the bottom of the nest box and reduced the mobility of the nestlings by fixing the wings to the body by a piece of tape glued to the lower side of the wings (fixing the feathers of the hand and arm of both wings together) thereby preventing them from fluttering out of the nest. In addition, we put a piece of tape around the tarsi to keep the offspring from hopping out of the nest. This prevented them from leaving the nest, but allowed them to move around in the nest and beg normally. After the experimental delay, we immediately removed all tape. To ensure that the fledglings of the experimentally delayed broods did not suffer a disadvantage, they were kept with the parents until day 45 when all individuals were transferred to group aviaries as for the control group. All birds experienced good health throughout the procedure as determined by their mass development and by visual inspection. To minimize the number of birds in this treatment, we chose only broods of one or two nestlings for the experimental treatment and limited the number of experimental broods to five (Table 1). We recognize that focussing on small experimental broods limits the conclusions we can draw from our study because behavioural interactions may differ between parents and offspring when broods are larger, but with our approach we can prove the principle and minimize the number of manipulated individuals bearing in mind the need for the ethical treatment of experimental birds. 
Table 1: Comparison of control and experimentally delayed-fledging broods. Means \pm SD

\begin{tabular}{|c|c|c|c|c|c|c|c|}
\hline & $\begin{array}{l}\text { Number of } \\
\text { broods } \\
\text { (n) }\end{array}$ & $\begin{array}{l}\text { Brood size } \\
\text { at hatching }\end{array}$ & $\begin{array}{l}\text { Mass at } \\
\text { hatching } \\
{[\mathrm{g}]}\end{array}$ & $\begin{array}{l}\text { Brood size } \\
\text { at fledging }\end{array}$ & $\begin{array}{l}\text { Mass at fledging } \\
\text { [g] }\end{array}$ & $\begin{array}{l}\text { Age at fledging } \\
\text { [d] }\end{array}$ & $\begin{array}{l}\text { Age at first } \\
\text { independent feeding } \\
\text { [d] }\end{array}$ \\
\hline $\begin{array}{l}\text { Experimental } \\
\text { broods }\end{array}$ & 5 & $1.80 \pm 0.45$ & $0.69 \pm 0.05$ & $1.80 \pm 0.45$ & $10.0 \pm 0.73$ & $24.1 \pm 1.39$ & $26.4 \pm 2.1$ \\
\hline $\begin{array}{l}\text { Control } \\
\text { broods }\end{array}$ & 27 & $3.04 \pm 1.34$ & $0.70 \pm 0.08$ & $2.85 \pm 1.41$ & $9.49 \pm 0.69$ & $19.3 \pm 1.38$ & $24.4 \pm 3.1$ \\
\hline
\end{tabular}

Data on brood mass development on six additional broods of brood size one or two were taken from a former data set (Krause et al. 2011). Nestlings of these broods were weighed on day 17 (i.e., briefly before fledging naturally) and day 25, approximately 5-6 d after fledging, that is at the age when our experimental broods fledged.

Offspring were checked at minimum two times daily to ensure they were healthy and were weighed once a day. After fledging of the first nestling, 21 broods of the control group and all experimental broods $(\mathrm{N}=5)$ were video recorded for 60 min every other day until the oldest offspring had reached the age of $35 \mathrm{~d}$. The camera was positioned in such a way that all three perches in the cage, the feeding sites, and the nest entrance were visible. We evaluated the video sequences for the mean age at first independent food intake, that is pecking movement of a fledgling at the feeding site. We calculated for each brood the mean daily mass gain until fledging $\left[g^{*} / d\right]$.

\section{Statistical Analysis}

All analyses were conducted at the brood level. Mean mass at hatching was analysed using a general linear model (GLM) with treatment as factor and brood size at hatching as a covariate.

We analysed mean age at fledging using a GLM with treatment as factor and brood size at fledging as a covariate. Mean mass at fledging, mean daily mass gain until fledging, mean age at first food intake, and parental feeding outside the nest were analysed with a GLM with treatment as a factor and brood size at fledging as explanatory variable. Final models were obtained by stepwise exclusion of non-significant variables, while the factor treatment always remained in the final model. Residuals of data were checked for the assumption of normality using a KolmogorowSmirnov test with Lilliefors correction. All respective initial models are presented in the supplementary material (Table. Sla-d), as there is a recent debate whether to use initial models or selected models
(Forstmeier \& Schielzeth 2011). The mean age at first food intake was $\log$-transformed $(\log (x+1))$ to obtain a normal distribution. All tests were calculated using the SPSS statistical package, version 22 .

\section{Results}

Hatching mass did not differ between nestlings of the control and experimental treatment (Table. 1; GLM: Treatment $\left.\mathrm{F}_{1,30}=0.06, \mathrm{p}=0.81\right)$. Mass at fledging (Table 1) was not significantly different between the treatments, but was negatively related to brood size (GLM: Treatment $\mathrm{F}_{1,29}=0.38, \mathrm{p}=0.54$; brood size $\mathrm{F}_{1,29}=10.28, \mathrm{p}=0.003$; Fig. la).

The experimental treatment delayed fledging by approximately $5 \mathrm{~d}$, that is $25 \%$ of the normal time to fledging (Table. 1; GLM: Treatment $F_{1,30}=51.61$, $\mathrm{p}<0.0001)$. Non-quantitative observations showed that the handicapped young in our experimental broods tried hard to leave the nest. Offspring kept in the nest beyond the normal fledging time were of normal mass for their brood size categories (Table 1; Fig. 1b; same-sized control broods (brood size 1 or 2 ) fledged on day 19 weighed $9.77 \pm 0.54 \mathrm{~g} ; \mathrm{n}=10$ ). Fledglings of the five experimental broods were of the same mass on day 25 (see Table. 1) as fledged animals in six unmanipulated additional broods of the same size (day 25: $10.35 \pm 0.8 \mathrm{~g} ; \mathrm{n}=6$ ). Mean daily mass gain until fledging was affected by treatment and brood size (GLM: Treatment $\mathrm{F}_{1,29}=15.06, \mathrm{p}=0.001$; brood size $F_{1,29}=6.02, p=0.02$ ). We found no treatment effect on the age when fledglings began to feed independently (GLM: Treatment $\mathrm{F}_{1,24}=2.25$, $p=0.15$ ) as well as on the duration of parental feeding of fledglings outside the nest (GLM: Treatment $\mathrm{F}_{1,16}=1.07, \mathrm{p}=0.21$ ), but this conclusion is limited by the low power of the comparison.

\section{Discussion}

The experiment shows that parents continue feeding in the nest even after offspring have fully developed 

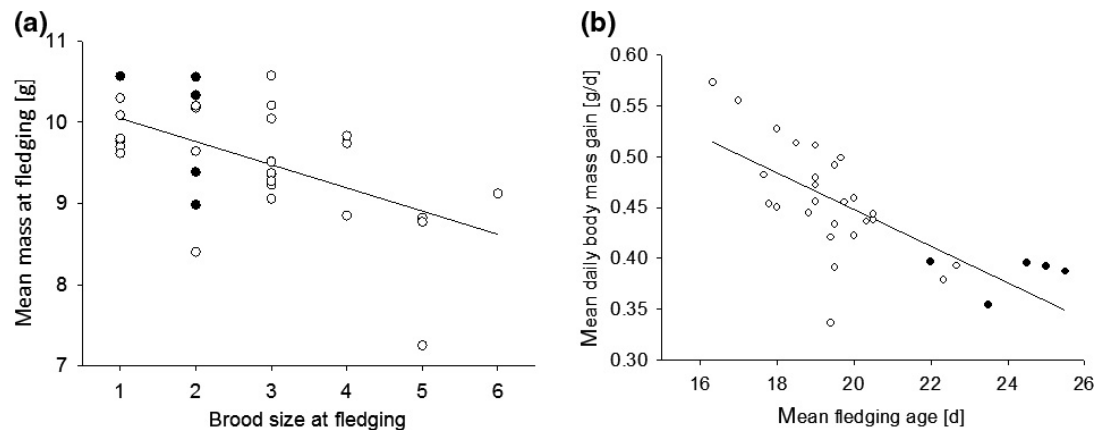

Fig. 1: Chick mass at fledging did not differ between groups. (a) Brood size was negatively linked to mass at fledging. (b) Daily body mass gain was negatively linked to age at fledging. Open circles indicate control broods, black circles experimental broods. See text for statistics.

the appearance and associated stimuli of a fledgling. This implies that chicks in the control group left the nest before parents would stop feeding inside the nest. Parents thus were unlikely to have encouraged young to leave the nest by reducing feeding intensity, as otherwise young of the delayed fledged group should have had lower fledgling mass than fledged young on day 25 . This suggests that there is little apparent conflict between parents and offspring over the timing of leaving the nest. It rather appears as if the offspring leave when they are ready for it. Thus, we conclude that proximally offspring control the time of fledging according to their age or developmental stage. Ultimately, offspring may benefit from fledging early by reducing the risk of nest predation (Ricklefs 1969; Martin 1995; Martin et al. 2000) or else, because once outside the nest they can obtain more food from parents than the siblings remaining in the nest (Soler et al. 2013) and start developing social skills as social group structure after fledging may affect subsequent development (Honarmand et al. 2015). In our experiment, the low number of experimental broods and their below average brood size chosen to minimize the number of chicks we had to manipulate for the experiment limit the power of our comparison. In particular, due to the use of small brood sizes for the experimental broods, we cannot exclude that behavioural interactions may differ between parents and offspring in larger broods. Nevertheless, this experiment provides a clear indication for the important role offspring play in the fledging decisions. In the following, we first discuss proximate causes of fledging and then how our results can be interpreted in ultimate, evolutionary terms.

Parent zebra finches showed great plasticity in the duration of nestling care. This is in line with the findings of Rehling et al. (2012), where the period of parental care at the nest had been shortened or lengthened via cross-fostering with older or younger chicks, but regardless all chicks fledged at the same absolute age. Thus, whether parents on their own adjusted the period of care to nestlings needs or whether they were induced by the reset of age-related nestling cues could not been disentangled by the experiments reported in Rehling et al. (2012). Our results allow us to separate between these two interpretations, as offspring in the delayed group displayed the morphological phenotype of post-fledging birds and were of the same mass as fledglings of the same age. Parents thus do not primarily rely on phenotypic traits in their decision to feed offspring in the nest, but appear to adjust the duration of parental nest care as long as chicks are in the nest which parents may take as an indicator of offspring need and locomotor abilities. The presence of offspring in the nest might thus be considered as a key phenotypic trait which the parents may have evolved to use as a stimulus to adjust parental care at the nest. However, even this interpretation would assume that, proximally, the actual fledging decision lies with the offspring. The fledglings from the delayed group appeared to start feeding independently at approximately the same age as those from the control broods. This might suggest that the onset of independent foraging is primarily age-dependent rather than experience-dependent, but the low power of our comparison precludes clear conclusions. Because zebra finch parents continue to feed fledglings, their direct costs of delayed fledging indeed may be low when sufficient food is available, that is when they do not have to invest in travelling between the nest and distant foraging sites like some seabirds (Johnsen et al. 1994; Riou et al. 2012). Given that parents in our experiment did not incur such travel costs, it thus seems adaptive not to encourage nestlings to leave the nest by reduced feeding. If long travel times and thus higher costs of feeding young at 
the nest rather than taking them to food sources, would result in 'less tolerant' parents is an interesting possibility to be addressed in future studies.

Nilsson \& Svensson (1993) (and later Soler et al. 2013) pointed out that the offspring's decision when to fledge may also be due to sib competition as early fledging by the oldest chick may allow this chick to pre-empt food brought to the nest site by parents. The early fledging decision may then be selected for by sibling conflict. On the other hand, Bowers et al. (2013) suggest that older siblings, in an act of cooperation, may actually delay fledging in nests with a particularly large age-spread thereby increasing their inclusive fitness by improving the survival chances of the younger siblings.

Reduced fledgling mass has been reported by Rehling et al. (2012) for experimental broods that had received younger nestlings to prolong the period of parental care, whereas broods which received older nestlings did not differ in fledging mass from controls. Parents that were already used to more intense begging of older nestlings may have adjusted their responsiveness downwards and, therefore, may have fed less in response to the reduced begging rates of cross-fostered younger chicks, resulting in lower mass at fledging (Muller \& Smith 1978). This could also explain the Soler et al. (2013) findings in a parallel experiment in magpies (Pica pica). Alternatively, parents could down-regulate feeding rate later in the nestling period as has been shown for the reed warbler (Grim et al. 2003; Grim 2007). However, given that our experimental broods displayed normal growth, this alternative interpretation appears less likely. Fledging mass is a crucial parameter linked to post-fledging survival that needs to be finely regulated in the interest of both, parents and offspring. In our experiment, mass at fledging and on day 25 was not different between chicks from the delayed and the control groups although the individuals from the respective groups differed significantly in age. Perhaps an optimal fledgling mass exists for zebra finches, as in the experiments by Rehling et al. (2012) fledglings from the older group were not significantly heavier than control birds, which is in accordance with our data where delayed chicks had similar fledging mass as controls, although they were approximately $5 \mathrm{~d}$ older. However, this question cannot be answered easily in such a laboratory study which provides ecologically less meaningful survival data, given that birds were under ad libitum feeding conditions with no predation pressure.
Our experiment is probing the mechanisms that evolved in a natural context by confronting the parents with a situation that will not normally occur in nature, except in the case of nests victimized by brood parasites (Grim et al. 2003). The experiment may be mimicking a natural situation in which offspring show delayed development or where extreme environmental (e.g. weather) conditions might not allow to leave the nest, and parents may need to extend the period of brood care to offspring in the nest. That the parents did so in our experiment may thus reflect an evolved, adaptive mechanism that ensures chick survival. So on an evolutionary timescale, the observed mechanism to leave the behavioural fledging decision to the offspring may represent a coevolved response to unpredictable food conditions.

Concerning offspring, nest predation is well known as an ecological factor determining the duration of the nestling period (Ricklefs 1969; Martin 1995; Martin et al. 2000). It has been less considered in behavioural research as a factor influencing the fledging decision. However, nest predation together with the cost of parental provisioning (for example in terms of the cost of travelling time during foraging) may play a major role in selecting who takes the fledging decision, parent or offspring. We would expect that parents are most flexible in open nesting species with short foraging distances as in most songbirds, because they can rely on their chicks urge to leave the dangerous nest as early as possible, that is the selective pressure to leave the nest is much greater on chicks than on parents. Although zebra finches have a domed nest (Griffith et al. 2008), they are subject to high levels of predation in the nest (approximately 60\%; Zann 1996). This is consistent with the hypothesis that predation risk is a major selecting force in the decision about the timing of fledging (Martin et al. 2000). Only a comparative study could show whether hole nesters are less flexible in response to an increased duration of parental care in the nest as their nestlings experience lower predation and may therefore be more likely to remain in the nest for longer than is optimal for the parents. We know of no published data on this question, but observations on great and blue tits, suggest that the parents outside are calling their chicks, apparently stimulating them to leave the nest (Perrins 1979, p. 163; P. Korsten, pers. comm.).

In conclusion, our experiment strongly suggests that on the proximate, mechanistic level in zebra finches offspring development determines the time of fledging, and the offspring probably fledge to avoid the greater risk of predation in the nest. 


\section{Acknowledgements}

We thank Benjamin Hennerkes for help during the data collection, Peter Korsten, Nikolaus von Engelhardt and Rudolf Jonker for critically reading and suggesting many improvements to the manuscript. ETK was funded by the Volkswagen Foundation (85994).

\section{Ethical Standards}

After the end of the experiment, all zebra finches remained in the laboratory stock. Breeding and housing of the birds was conducted with the permission of the Veterinäramt Bielefeld, Germany (\# 530.421630-1, 18.04.2002). The experimental manipulation was performed under permission of the LANUV, NRW, Recklinghausen (licence \# Az 87-51.04.2010.A027).

\section{Literature Cited}

Adam, I., Scharff, C. \& Honarmand, M. 2014: Who is who? Non-invasive methods to individually sex and mark altricial chicks. J. Vis. Exp. 87, e51429.

Bossan, B., Hammerstein, P. \& Koehncke, A. 2013: We were all young once: an intragenomic perspective on parent-offspring conflict. Proc. R. Soc. London B 280, 20122637.

Bowers, E. K., Sakaluk, S. K. \& Thompson, C. F. 2013: Sibling cooperation influences the age of nest leaving in an altricial bird. Am. Nat. 181, 775-786.

von Engelhardt, N., Carere, C., Dijkstra, C. \& Groothuis, T. G. G. 2006: Sex-specific effects of yolk testosterone on survival, begging and growth of zebra finches. Proc. R. Soc. London B 273, 65-70.

Forstmeier, W. \& Schielzeth, H. 2011: Cryptic multiple hypotheses testing in linear models: overestimated effect sizes and the winner's curse. Behav. Ecol. Sociobiol. 65, 47-55.

Forstmeier, W., Segelbacher, G., Mueller, J. \& Kempenaers, B. 2007: Genetic variation and differentiation in captive and wild zebra finches (Taeniopygia guttata). Mol. Ecol. 16, 4039-4050.

Gilby, A., Mainwaring, M., Rollins, L. \& Griffith, S. C. 2011: Parental care in wild and captive zebra finches: measuring food delivery to quantify parental effort. Anim. Behav. 81, 289-295.

Griffith, S. C., Pryke, S. R. \& Mariette, M. 2008: Use of nest-boxes by the Zebra Finch (Taeniopygia guttata): implications for reproductive success and research. Emu 108, 311-319.

Grim, T. 2007: Experimental evidence for chick discrimination without recognition in a brood parasite host. Proc. R. Soc. London B 274, 373-381.
Grim, T., Kleven, O. \& Mikulica, O. 2003: Nestling discrimination without recognition: a possible defence mechanism for hosts towards cuckoo parasitism? Proc. R. Soc. Lond. B 270, S73-S75.

Honarmand, M., Riebel, K. \& Naguib, M. 2015: Nutrition and peer group composition in early adolescence: impacts on male song and female preference in zebra finches. Anim. Behav. 107, 147-158.

Immelmann, K., Piltz, A. \& Sossinka, R. 1977: Experimentelle Untersuchungen zur Bedeutung der Rachenzeichnung junger Zebrafinken. Z. Tierpsychol. 45, 210-218.

Johnsen, I., Erikstad, K. E. \& Saether, B. E. 1994: Regulation of parental investment in a long lived seabird, the puffin, Fratercula arctica: an experiment. Oikos 71, 273278.

Kilner, R. M. \& Hinde, C. A. 2012: Parent-offspring conflict. In: The Evolution of Parental Care. (Royle, N. J., Smiseth, P. T. \& Kölliker, M., eds). Oxford University Press, Oxford, U.K., pp. 119-132.

Krause, E. T., Honarmand, M. \& Naguib, M. 2011: Zebra finch nestlings beg more under better nutritional conditions. Behaviour 148, 1239-1255.

Krause, E. T., Krüger, O., Kohlmeier, P. \& Caspers, B. A. 2012: Olfactory kin recognition in a songbird. Biol. Lett. 8, 327-329.

Leigh, D. \& Smiseth, P. T. 2012: Parent-offspring conflict over the transition to independence in Nicrophorus vespilloides: parental chemical cues and offspring begging. Ethology 118, 460-465.

Levrero, F., Durand, L., Vignal, C., Blanc, A. \& Mathevon, N. 2009: Begging calls support offspring individual identity and recognition by zebra finch parents. C. R. Biol. 332, 579-589.

Lindström, J. 1999: Early development and fitness in birds and mammals. Trends Ecol. Evol. 14, 343-348.

Litovich, E. \& Power, H. W. 1992: Parent-offspring conflict and its resolution in the European starling. Ornithol. Monogr. 47, 1-71.

Mainwaring, M. C. \& Hartley, I. R. 2012: Causes and consequences of differential growth in birds: a behavioural perspective. Adv. Study Behav. 44, 225-277.

Martin, T. E. 1995: Avian life history evolution in relation to nest sites, nest predation, and food. Ecol. Monogr. 65, 101-127.

Martin, T. E., Scott, J. \& Menge, C. 2000: Nest predation increases with parental activity: separating nest site and parental activity effects. Proc. R. Soc. London B 267, $2287-2293$.

Metcalfe, N. B. \& Monaghan, P. 2001: Compensation for a bad start: grow now, pay later? Trends. Ecol. \& Evol. 16, $254-260$.

Muller, R. E. \& Smith, D. G. 1978: Parent-Offspring Interactions in Zebra Finches. Auk 95, 485-495. 
Naguib, M., Riebel, K., Marzal, A. \& Gil, D. 2004: Nestling immunocompetence and testosterone covary with brood size in a songbird. Proc. R. Soc. London B 271, $833-838$.

Nilsson, J. A. \& Svensson, M. 1993: Fledging in altricial birds: parental manipulation or sibling competition? Anim. Behav. 46, 379-386.

Parker, G. A. \& MacNair, M. R. 1979: Models of parent-offspring conflict. IV. Suppression: evolutionary retaliation by the parent. Anim. Behav. 27, 1210-1235.

Perrins, C. 1979: British Tits. Collins, London, UK.

Rehling, A. \& Trillmich, F. 2007: Weaning in the guineapig (Cavia aperea f. porcellus): who decides and by what measure? Behav. Ecol. Sociobiol. 62, 149-157.

Rehling, A. \& Trillmich, F. 2008a: Changing supply and demand by cross-fostering: effects on the behaviour of pups and mothers in guinea pigs, Cavia aperea f. porcellus, and cavies, Cavia Aperea. Anim. Behav. 75, 1455-1463.

Rehling, A. \& Trillmich, F. 2008b: Maternal effort is state dependent: energetic limitation or regulation? Ethology 114, 318-326.

Rehling, A., Spiller, I., Krause, E. T., Nager, R. G., Monaghan, P. \& Trillmich, F. 2012: Flexibility in the duration of parental care: zebra finch parents respond to offspring needs. Anim. Behav. 83, 35-39.

Ricklefs, R. E. 1969: An analysis of nesting mortality in birds. Smithson. Contr. Zool. 9, 1-48.

Riou, S., Chastel, O. \& Hamer, K. C. 2012: Parent-offspring conflict during the transition to independence in a pelagic seabird. Behav. Ecol. 23, 1102-1107.
Roff, D. A., Remes, V. \& Martin, T. E. 2005: The evolution of fledging age in songbirds. J. Evol. Biol. 18, 1425-1433.

Smiseth, P. T., Wright, J. \& Kölliker, M. 2008: Parent-offspring conflict and coadaptation: behavioural ecology meets quantitative genetics. Proc. R. Soc. London B 275, 1823-1830.

Soler, M., Perez-Contreras, T. \& de Neve, L. 2013: Magpies do not desert after prolonging the parental care period: an experimental study. Behav. Ecol. 24, 1292-1298.

Wong, J. W. Y. \& Kölliker, M. 2012: The effect of female condition on maternal care in the European earwig. Ethology 118, 450-459.

Zann, R. A. 1996: The Zebra Finch-A Synthesis of Field and Laboratory Studies. Oxford University Press, Oxford.

\section{Supporting Information}

Additional supporting information may be found in the online version of this article:

Table S1: (a) Initial GLM prior to backward selection for hatching mass (d0), (b) Initial GLM prior to backward selection for mean age of fledging, (c) Initial GLM prior to backward selection for mean age of first food intake (log-transformed), (d) Initial GLM prior to backward selection for mean duration of parental feeding outside the nest. 